\title{
Modelling the adoption of different types of irrigation water technology in Alberta, Canada
}

\author{
S. Wheeler ${ }^{1}$, H. Bjornlund ${ }^{1,2}$, T. Olsen ${ }^{1}$, K. K. Klein ${ }^{2} \&$ L. Nicol ${ }^{2}$ \\ ${ }^{I}$ Centre for Regulation and Market Analysis, School of Commerce, \\ University of South Australia, Australia \\ ${ }^{2}$ Department of Economics, University of Lethbridge, Canada
}

\begin{abstract}
This paper analyses farmers' adoption of hard and soft technology in relation to irrigation technologies, production changes and water management changes in Alberta, Canada. Greater significance was found in modelling the adoption of hard technology (such as irrigation infrastructure technologies) than modelling the adoption of soft technology (water management or irrigation area changes). Overall, some of the most important influences include farm size, irrigation technology, off-farm income and being a member of an irrigation district. Few socio-economic variables were found to be important. Adoption of soft technology most likely leads to greater water efficiencies and in the future greater attention should be paid to a wider variety of factors and influences in order to model water management and trading behaviour.
\end{abstract}

Keywords: hard and soft irrigation water technology, water management skills, water trading, Alberta, Canada.

\section{Introduction}

Due to increased water scarcity and escalating environmental problems across the globe there is an increased push to reduce water use and improve water use efficiency, especially for irrigation [1]. Some areas in Canada have faced increasing water shortages since the early 1990s, with irrigators traditionally being the largest water consumer. The majority of irrigated land in Canada is in Alberta (64\%), with most of this irrigation in the South Saskatchewan River Basin (SSRB) and it accounts for $71 \%$ of consumptive use of surface water [2]. 
The majority of irrigators in southern Alberta are members of organized irrigation districts. Those who are members in irrigation districts account for $82 \%$ of total irrigators and about three-quarters of land under irrigation. They pay a flat fee per hectare to the irrigation districts to cover their share of administration, maintenance and some infrastructure rehabilitation costs. Irrigation districts hold the water licenses and manage the supply infrastructure. Private irrigators have individual water licenses and obtain water from various rivers within the SSRB; they are responsible for all infrastructure needed to pump the water from the river and convey it to their fields as well as the irrigation infrastructure in the fields [3]. Neither type of irrigator pays for the water, the cost of head works and the supply infrastructure. Water licenses are tied to the land and, historically, have remained with the property when the land was sold [4].

Although water use efficiency in Alberta has increased over time thanks to the adoption of more efficient water use technologies (a movement away from surface irrigation to wheel-move and then to high pressure and low pressure centre pivots), water resources in the SSRB have been found to be fully or overcommitted, with pressure on the water resource expected to worsen over time due to predicted population and economic growth as well as increased environmental demand and climate change. Improving irrigation equipment and water management practices can reduce the need for water.

It is important to know which factors influence the adoption of improved irrigation technologies on farms before an effective policy can be designed. The purpose of this study is to determine the influences on the irrigation technology and management practice adoption in Alberta, in particular focusing on the difference between the adoption of hard and soft water technologies.

\subsection{Adoption of new technologies in agriculture}

Many studies have investigated the factors that influence farmers' adoption of new technologies [5-9]. The general findings have been that early adopters of new technologies tended to be younger, more educated, more cosmopolitan, have higher incomes, larger farm operations, are leaders within the community, and more reliant on primary sources of information [10]. The expected profitability of new technologies also has consistently been shown to be linked with adoption (as first shown by Griliches [5]).

New technologies can be of two distinct types: hard and soft technologies (also described as embodied and disembodied technologies). Hard technologies are defined as those innovations where adoption involves buying/installing a physical input or output, while soft technologies involve the farmer acquiring new skills or rearranging their farm management or decision making in some way. These technologies can be easier than others for farmers to adopt (information is more readily available) because they involve a physical tangibility that can be experienced immediately. On the other hand, learning new skills or changing farmers' mindsets about management issues may be influenced by different sociological factors [11] and hence adoption is more difficult to predict. Data on soft technologies are often more difficult for farmers 
to obtain because there are fewer commercial benefits involved and, hence, reduced marketing and information provided by agricultural organisations. This is especially true for innovations with high environmental benefits and may also be true for changing water management practices that involve a range of private and public benefits. Water management practices can involve the implementation of catchment-wide practices that have a range of externalities associated with them.

In this study, we distinguish between different forms of hard and soft water technologies. The forms of hard water technology discussed here include surface irrigation, wheel move irrigation, pivot irrigation (with high and low pressure systems) and the use of computer panels to operate the pivots. The adoption of more efficient irrigation systems allows a higher proportion of water to be applied to crop root zones, hence increasing the level of water consumption for crops at a given level of water application. As such, irrigators can meet the consumptive needs of the plants while reducing their overall water use, thereby increasing their water use efficiency [12]. It is important to note that our definition of hard water technology traditionally falls more into a soft technology grouping in the agricultural adoption literature. This is because irrigation scheduling systems and water efficiency technologies increasingly are promoted with an environmental rationale, with the idea that they would reduce water usage within the catchment area. Because of these benefits, they would often be described as soft technologies in the literature. However, the water saving argument from adoption of new irrigation technologies is far from certain, as discussed later. The forms of soft water technology include production changes (increasing/decreasing irrigation); soil monitoring assessment (using visual crop condition, hand auger and feel method, or soil moisture instruments); irrigation scheduling techniques (use of irrigation or climate models); and the use of private consultants.

There has been considerable research on the adoption of irrigation technologies on farms [1, 12-21]. Scheierling et al. [22] found irrigation technologies were more likely to be adopted when adoption costs were lower, on land of lower quality and on crops of higher quality. Moreno and Sunding [15] found that drip technology was adopted on land with a higher gradient and poorer water retention capacity. On the other hand, Zhou et al. [13] found adoption of water saving technology higher on land with better water holding capacity.

Increasing the price of water has been identified as a key incentive for irrigators to adopt water-saving irrigation systems [15]. Their findings were supported by Carey's and Zilberman's [23] model which showed that random events like drought encouraged farmer adoption of modern irrigation technologies. Lower quality water also has been found to lead to adoption of more technically efficient irrigation methods [12]. However, the existing literature on the adoption of improved irrigation technologies tends to emphasize price as an indicator of scarcity rather than actual measures of physical scarcity.

Much of the relevant literature on irrigation technologies has been based on conditions in Israel or the United States, and there has been less research in 
Canada. On the other hand, there have been comparatively fewer studies on changes to water management in the literature [e.g. 24-25]. This limited literature suggests that the adoption of best management irrigation is not widespread and there is considerable capacity for improvements in practices. Deng et al. [14] investigated the challenges for water saving in agriculture in China, and highlighted the need to breed new varieties for high water use efficiency. As the review by Pereira et al. [26] on water irrigation management under water scarcity indicated, there is a need to develop appropriate methodologies for the analysis of social, economic, and environmental benefits of improved irrigation management.

\section{Methods}

\subsection{Data and methodology}

The data used in this study were obtained from two surveys, one of private and one of district irrigators in southern Alberta. Telephone interviews were conducted with 150 private irrigators in March 2007 [5]. Irrigators were randomly selected from a list of names and locations provided by Alberta Environment. The survey of farmers in the irrigation districts was conducted in 2006, with questionnaires sent by mail to 810 irrigators (320 in the Raymond Irrigation District and 490 to the Taber Irrigation District) [5]. 150 questionnaires were returned $(21 \%$ and $17 \%$ response rate from Raymond and Taber, respectively).

Both surveys asked for information on past, current and planned initiatives in adoption of new irrigation technologies, production, water management and energy use (and barriers to further improvements), in three distinct time periods: historical (prior to 2001), recent past (2001-2006) and future (2007-2012).

Binary probit analysis was used to examine the factors influencing adoption of past and future irrigation technologies and management practices, classified into hard or soft technologies. Binary probit models are appropriate when the dependent variable to be evaluated is dichotomous. If a farmer had adopted a form of technology/management change prior to 2006 (i.e. they had either adopted prior to 2001 or from 2001 to 2006 in the survey categories), then these farmers were categorized as adopters and were coded as 1 , and other farmers were categorized as non-adopters and coded as 0 .

Five broad categories of irrigator adoption of hard technologies were modelled, namely: a) conversion from surface to wheel move; b) conversion from wheel move to pivot; c) conversion from surface to pivot; d) conversion from high pressure to low pressure pivots; and e) purchase of a computer panel for pivot. Water management (soft technology) questions included: a) monitor soil moisture using visual crop condition or hand auger and feel method or start using soil monitoring instruments; b) start to turn water on and off and/or monitor position of pivots using computer or phone; c) start to use Alberta Irrigation Management Model (AIMM) or Irrigation Management Climate Information Network (IMCIN) to schedule irrigation; and d) start to use private consultants to support irrigation decision making. 
Table 1: $\quad$ Variable summary.

\begin{tabular}{|c|c|}
\hline Abbreviation & Explanation \\
\hline Surfacewheel & Convert from surface to wheel move irrigation, $1=$ adoption, 0 non-adoption \\
\hline Wheelpivot & Convert from wheel move to pivot irrigation, $1=$ adoption, $0=$ non-adoption \\
\hline Surfacepivot & Convert from surface to pivot irrigation, $1=$ adoption, $0=$ non-adoption \\
\hline Highlow & $\begin{array}{c}\text { Convert from high to low pressure irrigation system, } 1=\text { adoption, } 0=\text { non- } \\
\text { adoption }\end{array}$ \\
\hline Comppiv & Purchase computer panel for pivot, $1=$ adoption, $0=$ non-adoption \\
\hline Visualcrop & $\begin{array}{l}\text { Monitor soil moisture using visual crop condition, where } 1=\text { adoption, } 0=\text { non- } \\
\text { adoption }\end{array}$ \\
\hline Handauger & $\begin{array}{c}\text { Monitor soil moisture using hand auger and feel, } 1=\text { adoption, } 0=\text { non- } \\
\text { adoption }\end{array}$ \\
\hline Soilmonitor & $\begin{array}{l}\text { Monitor soil moisture using soil monitoring instruments, } 1=\text { adoption, } 0=\text { non- } \\
\text { adoption }\end{array}$ \\
\hline Compphpiv & $\begin{array}{l}\text { Use computer or phone to monitor pivot position, } 1=\text { adoption, } 0=\text { non- } \\
\text { adoption }\end{array}$ \\
\hline AIMM & Use AIMM or IMCIN to schedule irrigation, $1=$ adoption, $0=$ non-adoption \\
\hline Consult & $\begin{array}{l}\text { Use private consultants to support irrigation decision making, where } 1= \\
\text { adoption, } 0=\text { non-adoption }\end{array}$ \\
\hline Own & $1=$ owner of irrigated land; 0 otherwise \\
\hline Age & $25=$ under 34 years; $45=$ between 35 and 54 years; $65=$ over 55 years \\
\hline Farmy & $\begin{array}{c}5=\text { has been involved with farming less than } 10 \text { years; } 17=\text { involved between } 11 \\
\text { and } 24 \text { years; } 30=\text { involved more than } 25 \text { years }\end{array}$ \\
\hline Parent & $1=$ parents in farming; 0 otherwise \\
\hline Child & $1=$ expect a member of family to take over farm; 0 otherwise \\
\hline edu & $\begin{array}{c}9=\text { not completed high school; } 12=\text { completed high school; } 15=\text { undergraduate } \\
\text { university degree or college degree; } 17=\text { postgraduate degree }\end{array}$ \\
\hline Offfarm & $1=\mathrm{a}$ member of the household had off-farm work; 0 otherwise \\
\hline offarminc & The percentage of income derived from off-farm work \\
\hline dryland & Number of dryland acres on farm \\
\hline irrig & Number of irrigated acres on farm \\
\hline Priv & $1=$ private irrigator; $0=$ district irrigator \\
\hline Qual & $1=$ farmer is concerned about irrigation water quality; 0 otherwise \\
\hline Pctcer & Percentage of irrigated acres producing cereals \\
\hline Pctsc & Percentage of irrigated acres producing speciality crops \\
\hline Pctgrav & Percentage of acres irrigated by gravity \\
\hline Pctwm & Percentage of acres irrigated by wheel move \\
\hline Pctlpp & Percentage of acres irrigated by low pressure pivot \\
\hline Pcthpp & Percentage of acres irrigated by high pressure pivot \\
\hline Pctele & Percentage of acres irrigated using electricity \\
\hline Pctng & Percentage of acres irrigated using natural gas \\
\hline Pctdie & Percentage of acres irrigated using diesel \\
\hline Pctpro & Percentage of acres irrigated using propane \\
\hline
\end{tabular}


Estimation of the binary probit model was based on maximum likelihood. The estimated coefficients represent the impact of a one-unit change in the independent variable in question, holding the other explanatory variables constant, on the log of the probability of a given choice, not on the probability itself. Definitions of all variables are provided in Table 1.

A range of farmer socioeconomic demographic variables, farm characteristics, current irrigation practices (irrigation types and energy uses) and farmer beliefs/attitudes were included in our models. In the models explaining the adoption of new irrigation technologies, ownership of irrigated land is expected to have a positive impact on adoption since the returns to investment mainly accrue to land owners.

As physical hard technologies tend to be long-run investments; the sign of the estimated owner coefficient is expected to be positive; while soft water management practices are skills based, transferable and hence are more like short-term investment, the owner coefficient is expected to be negative.

In general, the older a farmer is, and the longer the farmer has been farming, the slower the farmer is expected to be in adopting new innovations. However, the latest anecdotal evidence from Alberta suggests that older farmers adopt newer irrigation technology because older types of irrigation such as flood and wheel move require too much physical activity, hence it is expected that there will be an opposite difference between the age coefficient effect in the hard and soft technology models. It is also expected that if the farmer took over the farm from a parent, the farmer holds a traditional view on farming, which is a negative influence on the adoption of new technologies and management practices. The opposing argument is that if the farmer expects his/her children to take over the farm, adoption of new technologies should be greater because the benefits of the investments are kept in the family. It is expected that the more education a farmer has, the more likely he/she is to adopt new technology.

Off-farm income may pull adoption in both directions. Off-farm income provides an opportunity to finance technology investment and also affords more time for off-farm work as the new technology generally is less labour intensive. But, high off-farm income makes the farm less reliant on farm income and therefore the farmer may be unable to invest in new farm technology. The larger the size of the farm, the higher the expected returns, therefore the size of farm is expected to have a positive impact on adoption, though the size of the irrigated area should have more of an impact than the farm's dryland area. If a farmer is concerned about the quality of irrigation water, it is expected that the farmer is more likely to invest in new technologies that improve irrigation water management. The concern about water quality is a proxy for environmental awareness inducing more efficient water use. The coefficient for private is expected to be negative as irrigation within district is more intensive.

\section{Results}

Results are shown in Tables 2 and 3. Although the probit regression models predict only moderately well, they exhibit no problems with collinearity (though 


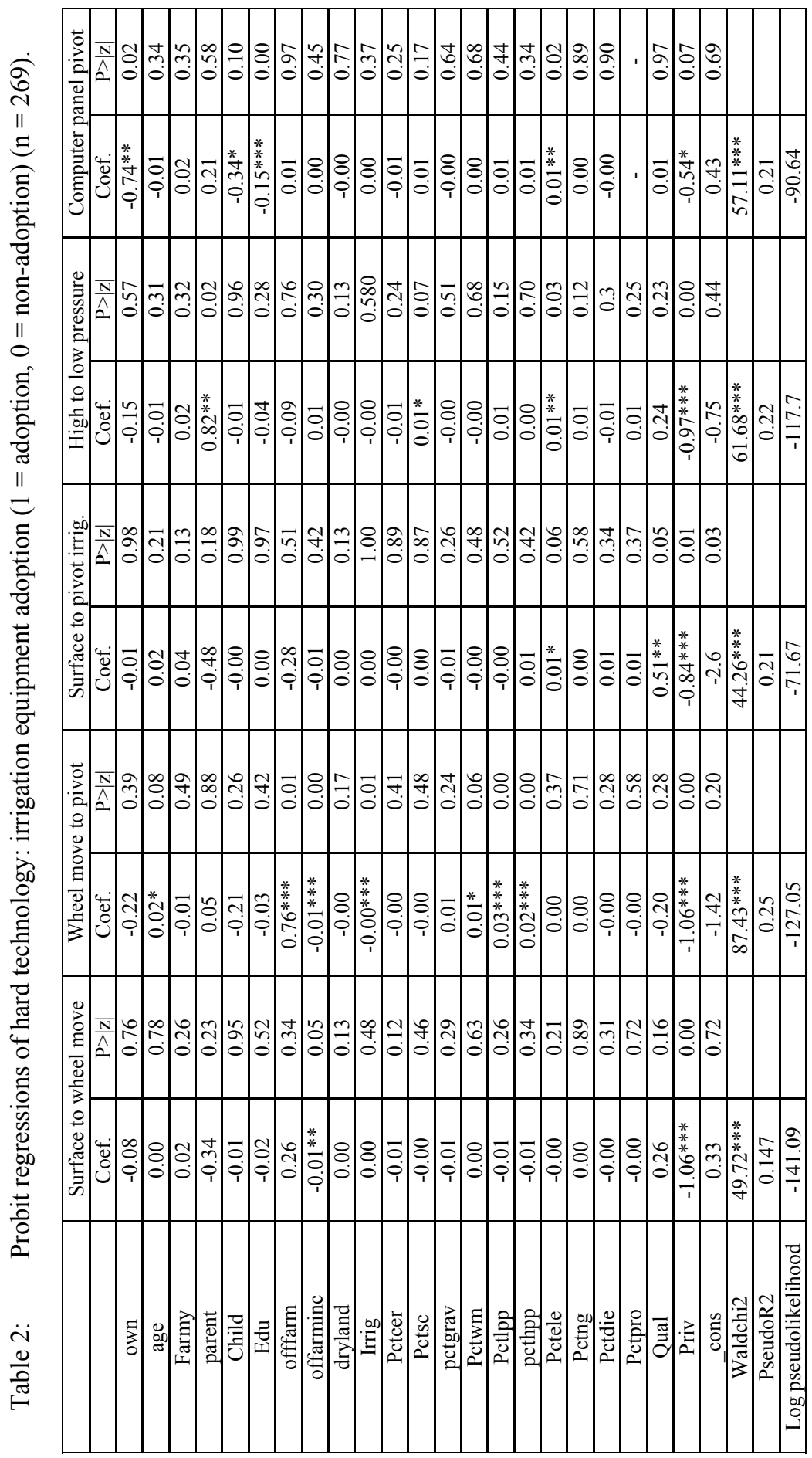




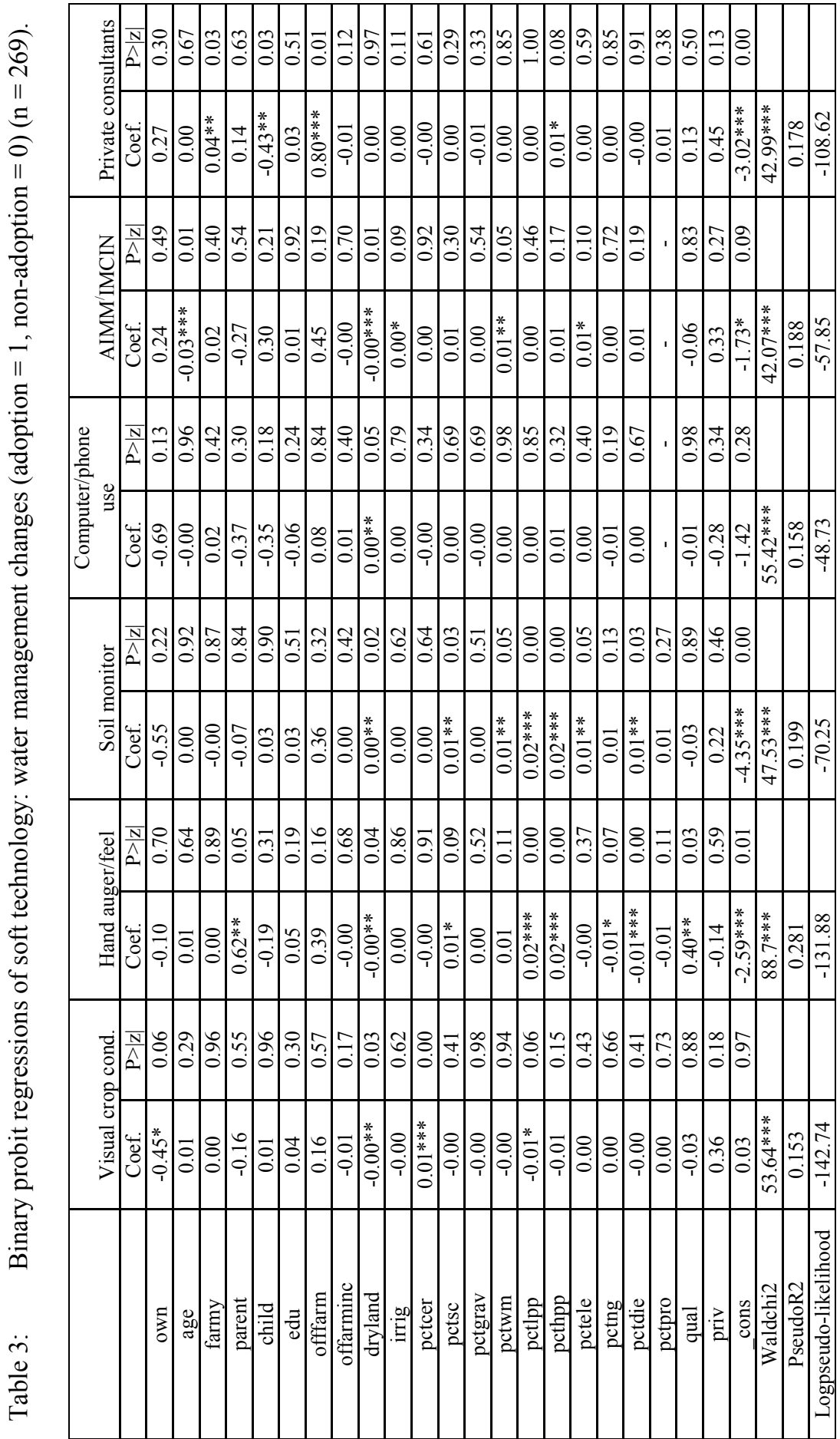


a number of variables were dropped initially from some models) and all were estimated with robust standard errors to minimize heteroscedasticity issues. There was more success achieved in modelling the adoption of hard technologies (i.e., actual equipment) rather than the adoption of soft technologies (changing water management practices). In general (where a variable was at least significant twice in Table 2 with the same sign), irrigators were more likely to have adopted new irrigation technologies if they: a) had a lower percentage of off-farm income as a source of total farm income; b) had a higher percentage of land irrigated by electricity; and c) were a member of an irrigation district. In general they were more likely to have adopted water management practices if they: a) had less dryland acres; b) had a higher percentage of land devoted to speciality crops; c) had a higher percentage of area irrigated by wheelmove or low (or high) pressure pivot using electricity.

In the tables, $\mathrm{a} * * *$ signifies significant at least at the 0.01 level, a $* *$ signifies significant at least at the 0.05 level and a * signifies significant at least at the 0.10 level. Similar low significance levels were achieved when modelling increases or decreases in the total area under irrigation (results not shown here). Irrigators were more likely to have increased their irrigated area if they had a lower percentage of area irrigated by gravity. Irrigators were more likely to have decreased their irrigated area if they: a) had a larger dryland area; b) had a smaller irrigated area; c) had a higher percentage of area with speciality crops; d) had a higher percentage of area irrigated by gravity, wheelmove, low or high pressure pivot; and e) were not concerned with the irrigation water quality. Irrigators were more likely to have adopted less water using crops (results not shown here) if they: a) did not have off-farm income (but the higher the percentage of off-farm income then the more likely that adoption would have occurred); b) had a larger irrigated area; c) had a higher percentage of area irrigated by wheelmove and high pressure pivot; d) had a lower percentage of area irrigated by electricity; and e) were not concerned with the irrigation water quality.

\section{Discussion}

These results confirm that modelling the adoption of skill-based or sustainable management activities requires careful attention to a variety of influences. The traditional variables used in economic models do not sufficiently explain farmers' actions and intentions. Greater consideration needs to be given to other factors, such as farmers' attitudes to their lifestyle, their farm desires, succession, environmental factors and community views. Perhaps there is an endowment or ownership utility effect attached to farm production, with greater disutility experienced by reducing production overall rather than increasing production.

One of the most consistently significant factors affecting the adoption of new water management technologies was whether the irrigator was private or a member of an irrigation district. Private irrigators clearly invest less in hard technologies, most likely because they rely less on high value irrigation crops to generate farm revenue, but rather use irrigation to produce feed to supply their main businesses such as feedlot or cow-calf operations. Generally, the larger the 
dryland area of the farm, the less likely it is that an irrigator adopted hard water technologies, although it has a positive effect on the adoption of some water management techniques. This suggests that the returns to the different water investments do depend to some extent on the size of the farm.

The next most important influences were the type of technologies already present on the farm. Farms that had already invested heavily in various irrigation technologies such as high or low pressure pivot were more likely to adopt improved water management practices. This is likely to reflect that these irrigators, already having the most efficient forms of hard water technology, are looking at soft technologies to further increase their efficiency. On the other hand, it is irrigators who have a higher percentage of their land irrigated by electricity who are more likely to adopt hard water technologies.

The next most important influence was if the farm had off-farm income, and the percentage of total household income derived from off-farm sources. The effect on technology adoption of earning off-farm income was not clear since both income and substitution effects affect it. The results show that having offfarm income increases the probability of adopting some hard and soft technologies (income effect) but having a larger percentage of total farm income derived from off-farm work can decrease adoption of some hard technologies (substitution effect). This indicates that when farmers have some off farm work they have an interest in being more efficient as it saves time; however, it seems that the higher the dependence on off-farm work the weaker their overall farm financial position and hence their ability to invest.

There were few socio-economic influences on the adoption of improved technologies. As hypothesized, younger farmers were more likely to have adopted soft water technology (such as sophisticated irrigation management models) as compared to older farmers who were more likely to adopt hard technologies for increased convenience (i.e. move away from wheel move to pivot). Education did not play that much of a role except in negatively influencing the adoption of one hard technology. Given that this result was unexpected, sensitivity testing of our education variable with dummy education variables found that having a graduate degree had a significant, positive effect on the adoption of soft technologies, reinforcing our conclusion of the importance of further education as a driver of adoption of more skilled-based technologies.

\section{Conclusion}

The need to improve irrigation water use efficiency and conserve water is a key issue within the South Saskatchewan River Basin in Alberta, Canada. Water use efficiency in the region may be improved by: a) improving irrigation equipment; b) improving water management practices; and c) reducing the irrigated area and/or changing production to less water consuming varieties or crops. Before any effective government policy on water use efficiency is designed, it is important to know what actually influences the adoption of improved irrigation technologies and how the adoption differs between different categories of hard and soft technologies. Hard technology was defined as those innovations where 
adoption involves buying/installing a physical input or output, while soft technology involves the farmer acquiring new skills or rearranging farm management in some way. The most important way that improved water use efficiencies is likely to occur is from adoption of soft technologies, in terms of reducing the area irrigated, improving irrigation scheduling, switching to less water consuming crops or varieties, or implementing water trading. Although no policy incentives may be required to increase the adoption of hard water technologies, given the primarily private benefits that accrue to irrigators, a range of instruments such as education, public extension and subsidy approaches may be necessary to encourage further adoption of soft water technologies.

Our results revealed that more significance was achieved in the models of hard technology (specifically, improved irrigation equipment) than soft technology (improving management practices and modifying irrigation/production areas), suggesting that the adoption of skill-based or sustainable management practices requires careful attention to a variety of influences. Greater consideration needs to be given to other factors, such as farmers' attitudes to their lifestyle, succession, environmental factors, community views, information sources, institutional influences, etc.

The most important influence on adoption seems to be the farms dependence on irrigation. District irrigators with a large proportion of their irrigated area in specialty crops and hence are very dependent on sufficient and timely irrigation are the ones most likely to adopt. On the other hand private irrigators with large areas of dry land farming and small irrigated areas are least likely to adopt as they are least dependent on irrigation. Having off-farm income and its importance in the overall farm total income had both an income and substitution impact on technology and skill adoption. Few socio-economic influences were found to significantly affect the adoption of hard or soft technologies.

\section{References}

[1] Seo, S., Segarra, E., Mitchell, P., \& Leatham, D., Irrigation technology adoption and its implication for water conservation in the Texas High Plains: a real options approach. Agricultural Economics, 38(1), 47-55, 2008.

[2] AENV, Alberta Environment. 2003. Water for life - Alberta's strategy for sustainability, Alberta Environment, Edmonton.

[3] Bjornlund, H., Nicol, L. \& Klein, K., Economic instrument and irrigation water management - a comparative study of private and district irrigators in Alberta, Canada. In Sustainable Irrigation - Management Technologies and Policies II, ed. Y. Esteve, C. Brebbia and C. Rico, pp. 3-14,2008.

[4] Bjornlund, H., Nicol, L. \& Klein, K., Challenges in implementing economics instruments to manage irrigation water on farms in Southern Alberta. Agricultural Water Management, 92(3), pp.131-41, 2007.

[5] Griliches, Z. Hybrid Corn: An exploration in the economics of technological change. Econometrica, 25(4), pp.501-21, 1957.

[6] Feder, G. \& Slade, R., The acquisition of information and the adoption of new technology. American Journal of Agricultural Economics, 66, pp. 312320, 1984. 
[7] Feder, G. \& Slade, R., The Role of Public Policy in the Diffusion of Improved Agricultural Technology. American Journal of Agricultural Economics, 67(2), pp.423-28, 1985.

[8] Guerin, L. \& Guerin, T., Constraints to the adoption of innovations in agricultural research and environmental management: a review. Australian Journal of Experimental Agriculture, 34(4), pp. 549-71, 1994.

[9] Rogers, E., Diffusion of Innovations, 5th ed., The Free Press: New York, 2003.

[10] Stephenson, G., The somewhat flawed theoretical foundation of the extension service. Journal of Extension, 41(4), pp.1-10, 2003.

[11] Morrison, M., Identifying market segments for technology adoption. 49th Conf. of the Australian Agricultural and Resource Economics Society, Coffs Harbour, NSW, 9-11th Feb 2005.

[12] Schuck, E., Frasier, W., Webb, R., Ellingson, L. \& Umberger, W., Adoption of more technically efficient irrigation systems as a drought response. Water Resources Development, 21(4), pp. 651-62, 2005.

[13] Zhou, S., Herzfeld, T., Glauben, T., Zhang, Y. \& Hu, B., Factors affecting Chinese farmers' decisions to adopt a water-saving technology. Canadian Journal of Agricultural Economics, 56(1), pp. 51-61, 2008.

[14] Deng, X., Shanc, L., Zhang, H. \& Turner, N., Improving agricultural water use efficiency in arid and semiarid areas of China. Agricultural Water Management, 80(1-3), pp.23-40, 2006.

[15] Moreno, G. \& Sunding, D., Joint estimation of technology adoption and land allocation with implications for the design of conservation policy. American Journal of Agricultural Economics, 87(4), pp. 1009-19, 2005.

[16] Schuck, E. \& Green, G., Field attributes, water pricing, and irrigation technology adoption. Journal of Soil and Water Conservation, 56(4), pp. 293-98, 2001.

[17] Green, G., Sunding, D., Zilberman, D. \& Parker, D., Explaining irrigation technology choices: a microparameter approach. American Journal of Agricultural Economics, 78(4): pp.1064-72, 1996.

[18] Caswell, M. \& Zilberman, D., The choices of irrigation technologies in California. American Journal of Agricultural Economics, 67(2), pp.224-34, 1985.

[19] Caswell, M., Irrigation Technology adoption decisions: Empirical evidence. In The Economics and Management of Water and Drainage in Agriculture, ed. A. Dinar \& D. Zilberman, Kluwer Academic Publishers, Boston, pp.295-312, 1991.

[20] Shrestha, R., \& Gopalakrishnan, C., Adoption and Diffusion of Drip Irrigation Technology: An Econometrics Analysis. Economic Development and Cultural Change, 41(2), pp.407-18, 1993.

[21] Negri, D. \& Brooks, D., Determinants of irrigation technology choice. Western Journal of Agricultural Economics, 15(2), pp.213-23, 1990.

[22] Scheierling, S., Loomis, J. \& Young, R., Irrigation water demand: A metaanalysis of price elasticities. Water Resources Research, 42(1), W01411, doi:10.1029/2005WR004009, 2006. 
[23] Carey, J. \& Zilberman, D., A model of investment under uncertainty: modern irrigation technology and emerging markets in water. American Journal of Agricultural Economics, 84(1), pp. 171-83, 2002.

[24] McCrea, R. \& Rivers, M., Sustainable irrigation - a collective effort for regional development. Proc. of the Int. Conf. of the Network of Regional Governments for Sustainable Development. Fremantle, Western Australia, 2003.

[25] Bauder, T., Waskom, R., Frasier, M. \& Hoag, D., Irrigation best management practices: What are Colorado producers using? Fact sheet \#19, Colorado State University, 1997.

[26] Pereira, L., Oweis, T. \& Zairi, A., Irrigation management under water scarcity. Agricultural Water Management, 57(3), pp.175-206, 2002. 